\title{
Program Research Project Grants
}

National Cancer Institute

\section{Source}

National Cancer Institute. Program Research Project Grants. NCI Thesaurus. Code C18922.

The program project grant is an institutional award made in the name of a program director for the support of a broadly based, long-term, multidisciplinary research program that has a well-defined central theme, research focus, or objective. The grant funds at least three interrelated projects and, often, core resources that support at least three projects at all times. Interrelationships and synergism among component research projects should result in greater scientific contributions than if each project were supported through a separate mechanism. The grant is based on the concept that projects closely related to a central theme can be conducted more effectively and efficiently through a coordinated, collaborative, multidisciplinary approach. 